\title{
Research on Complex Energy Production System for the Marine Environment Supervising Buoy
}

\author{
SuYeong Yang, NamHyun Yoo and WonJung Kim \\ Elsys Co., Ltd., Dept. of Naval Architecture, Ocean, and IT Engineering, \\ Kyungnam University, Dept. of Computer Engineering, Sunchon National \\ University \\ kwj@sunchon.ac.kr
}

\begin{abstract}
Recently, aerial drone technology is widely introduced for easily monitoring the marine environment. Aerial drones are being considered due to the advantages including the monitoring capability of wider region for a long time and no restriction to power source for supplying electricity for a long time. Likewise, the reason for actively considering aerial drones for marine environmental monitoring use is due to the chronic restrictions that the traditional floating buoy has. In operating floating buoys real time around the clock all year round, to be able to transmit this data externally real time or save for a certain period of time by using internal storage, continuous power supply was essential. But due to the restriction from the location of floating buoys, the size of buoys and excessive cost for access, there were many restrictions compared to land and aerial environments. To resolve the power issue, various measures were explored such as assisting power supply by using maritime energy source such as solar power, wind power or tidal power or operating ultra low power systems. In this study, the energy harvesting system and power management algorithm for complex energy production system using solar power, wind power and tidal power used for operating floating buoys were designed and developed. By using this system, the electricity management system of each power source that has been previously managed individually is managed as an integrated system with capability of more efficient power management and supply, hence extending the operation hours of floating buoys while providing stable power supply.
\end{abstract}

Keywords: Ocean Buoy, Complex Energy Management System, Harvesting System, Photovoltaic System, Wind Power System, Wave Power System

\section{Introduction}

The maritime environment takes over $70.8 \%$ of surface space of earth. Due to lack of crop cultivating space from increased population and expansion of cities from industrialization, the space for cultivating crops is rapidly decreasing. To solve this problem, the demand for the maritime environment monitoring to expand marine farming using the marine environment and the role for source of new renewable energy is consistently increasing. In particular, recently, beyond the monitoring on pollution issues on the maritime environment, the monitoring is being expanded to diverse range including monitoring of marine resources, marine energy source and navigation information of ships. Unlike land, due to the distance from monitoring space, location restriction, lack of stable electricity supply and insufficient maritime facility, various alternatives are being explored by using aerial drones and satellites, but the most basic tool used for monitoring the maritime environment is floating buoy. Buoys are installed in the maritime environment and many researches have been conducted on the stability of floating devices, anticorrosion property and stable power supply equipment. In particular, recently, solar, 
tidal or small wind power generators are used as standalone or to assist batteries that are the most basic power supply source.

In this study, the complex energy production system for providing longer power supply hours and stable power management by integrating solar, tidal and small wind power generators that have been used in existing floating buoys was designed and developed. In chapter two, the buoy for monitoring the maritime environment and related researches will be introduced, design and development of this system in chapter three, and the power generation algorithm for the complex energy production system developed in this study will be introduced in chapter four.

\section{Related Work}

\subsection{Floating Buoy}

Floating buoys are best utilized in US. US has developed large buoys measuring $12 \mathrm{~m}$ since 1960 s by NDBC of NOAA for operation and recently, the compact buoys are performing monitoring of maritime climate, change in the maritime environment, monitoring fish resources, surveying marine pollution, monitoring tsunami and monitoring borders. Japan has produced large buoys measuring as large as 10m since 1970s and has continuously used in systems for monitoring the open sea. And Norway, one of the power nations in marine products, has developed various buoys for use in fish farm monitoring systems. Also, Datawell in Netherlands has commercialized wave observation buoys for international use [1].

In Korea, to monitor the maritime environment, maritime environment observation buoy, weather radar, microwave radio repeater system and underwater environment monitoring system are being developed, and recently, the researches on monitoring of red tide and marine spilt oil are being continued [1-5].

Figure 1 shows TRIAXYS Wave Buoy for monitoring the maritime environment using tidal power, and Figure 2 shows the electricity management system for TRIAXYS Wave Buoy [5-6].

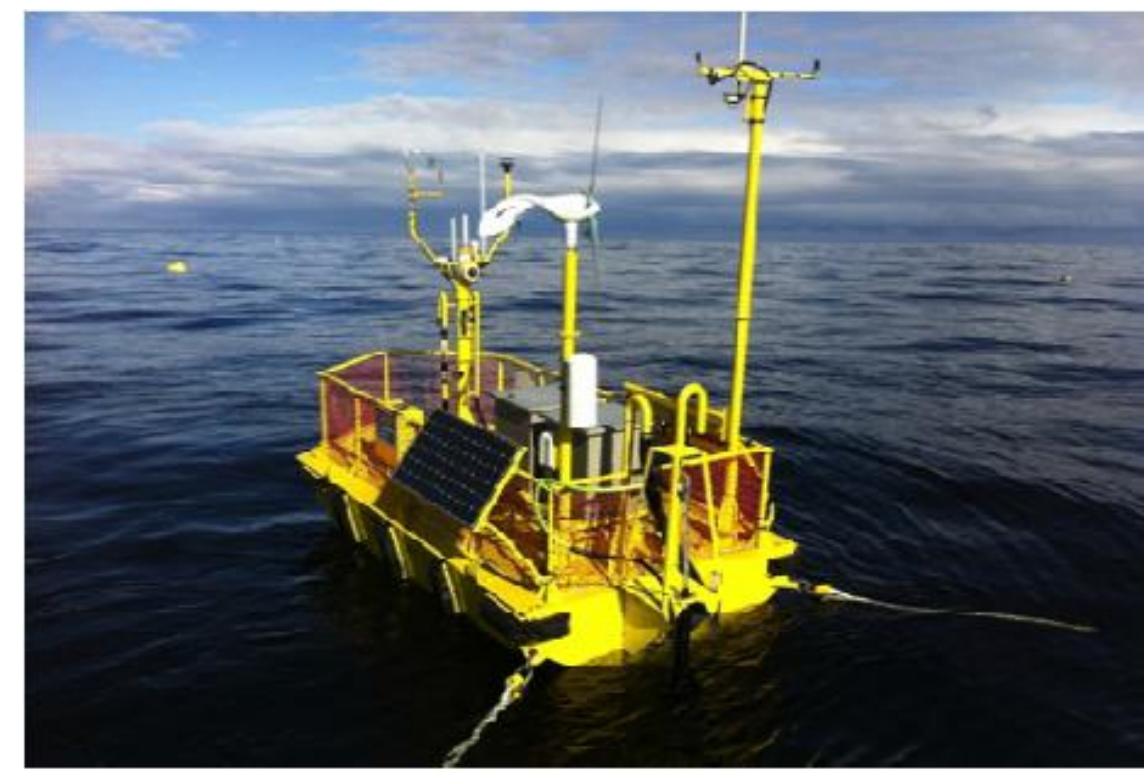

Figure 1. TRIASYS Wave Buoy 


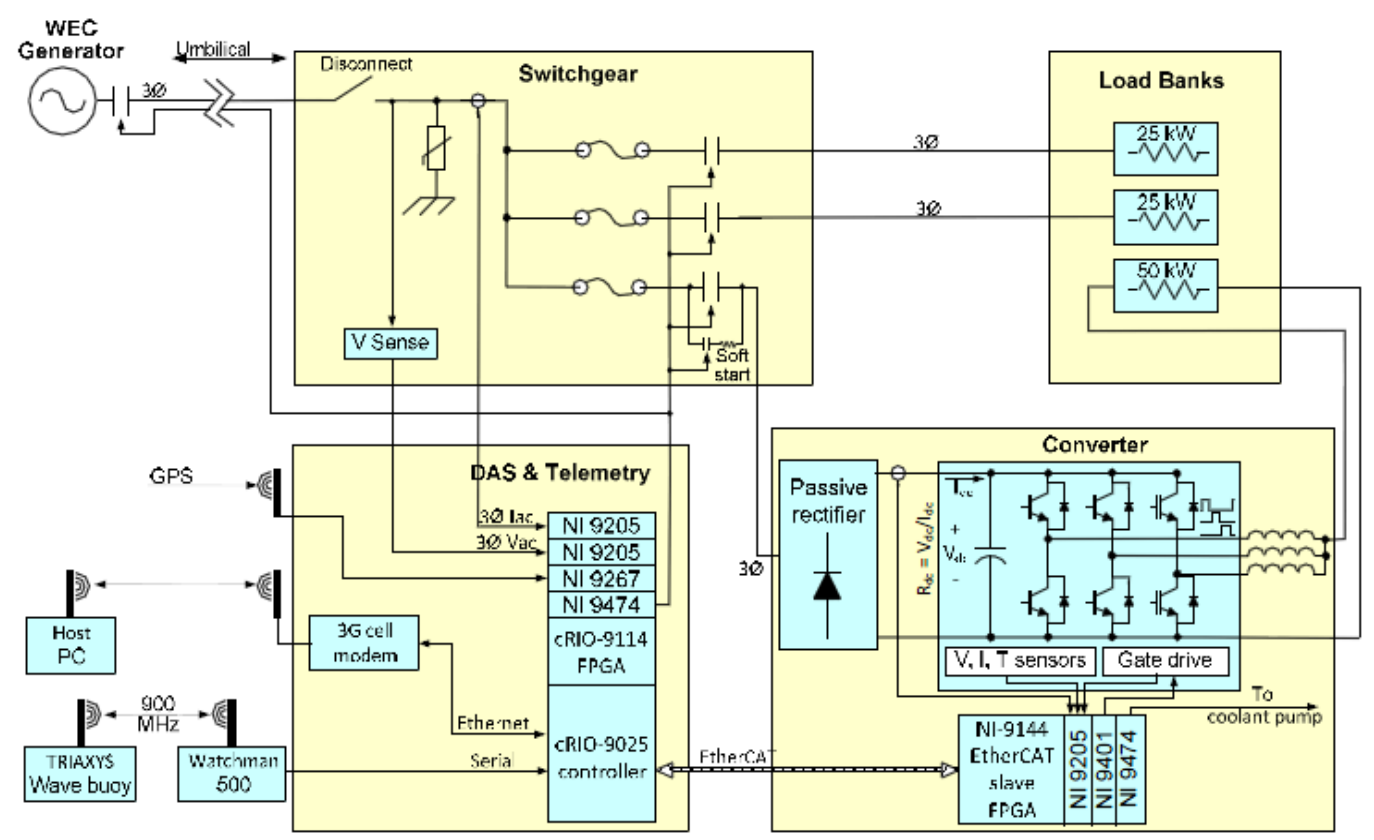

Figure 2. Power Management Systems for TRIASYS Wave Buoy

\subsection{Fish Farm Environment Monitoring System}

Recently, due to the climate change from global warming, reduction in fish species resource, expansion of typhoons and increase in water temperature, the demand for securing fish species resource using fish farms is consistently increasing from catching fish by using net. In particular, in Norway and Chile, the secondary or tertiary industrialization on fish farming industry that has once been first industry has been conducted by applying ICT and robot technology, and recently, they are leading change into sixth industrialization. The core technology required for secondary or tertiary industrialization of farming industry is ICT, and floating buoy using this is also a basic element. In Korea, to develop the farming industry, many attempts in [7], [8], and [9] were made since late 2000s. As for [8], the specialized terminal based on remote communication for managing the fish farm history was developed as an attempt to easily enter and manage sensors installed to floating buoys, breeding log, health diagnosis record, purchasing log (fresh feed, assorted feed, drugs, vaccine and additives) and additional fish species record. Figure 3 shows the prototypes for specialized terminal attempted in [8].

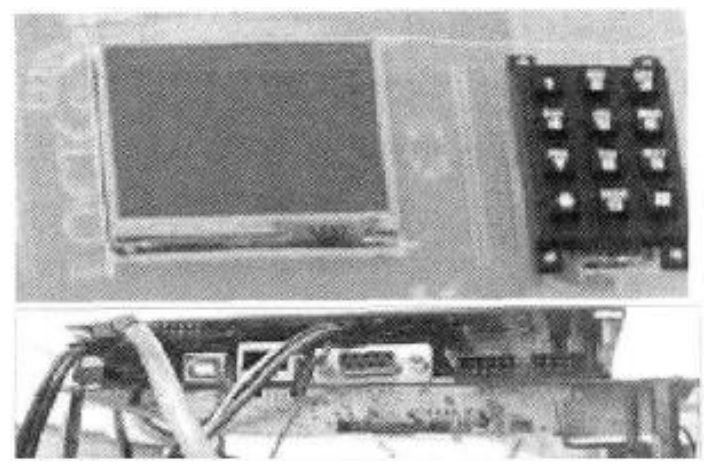

Figure 3. Test Mobile Kit for Traceability System 
In [9], to manage the fish farms installed in open sea, the development of a system for real time monitoring on fish farm environment from image on system for exchanging text based information was attempted. In [9], the plane earth model on wireless LAN was used to receive image data by using land server system from cameras installed to monitor fish farm, and the feasibility was verified. Figure 4 shows the structure of [9].

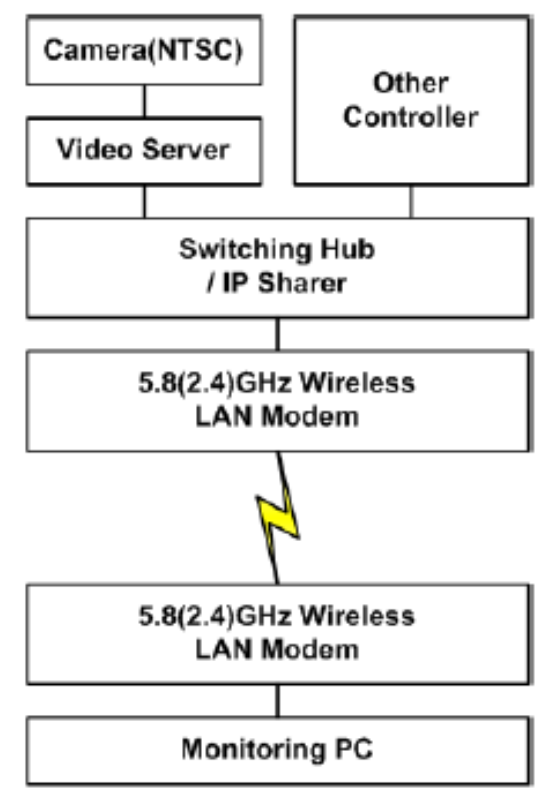

Figure 4. Wireless Vision Monitoring System

In [10], to prevent theft in floating fish farm, a system capable of alarm and tracking functions to robbery and theft invading fish farm for 24 hours using F-AIS and electronic navigation chart installed on fishing vessel as well as X-Band alpha radar with $9 \mathrm{GHz}$ range was developed. Figure 5 shows the system structure of [10].

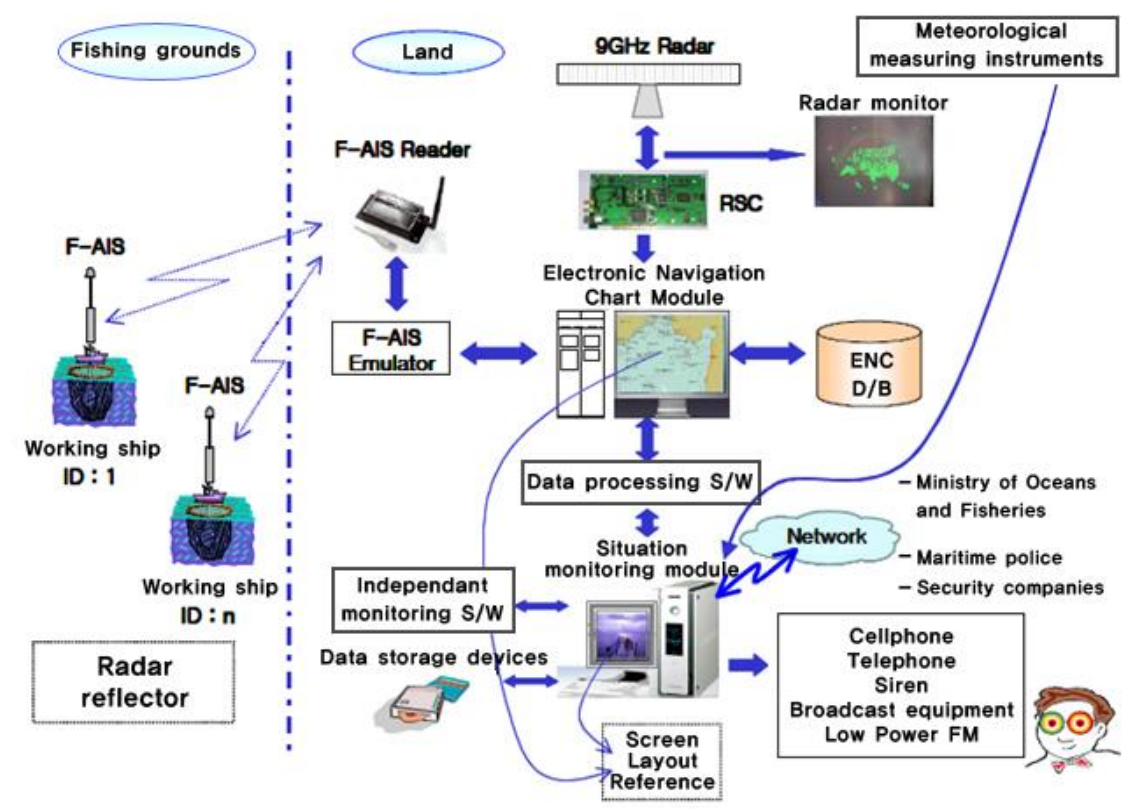

Figure 5. Structure of Fish Farm Theft Prevention System 
Apart from these, in Tongyeong and Jeju Island, in combination of various ICT technologies, the fish farm environment is monitored real time and remotely controlled based on this to resolve the issue of lack of operating personnel in fish farms and fish are fed and injected of drugs at the optimum timing to improve the quality of fish produced [11].

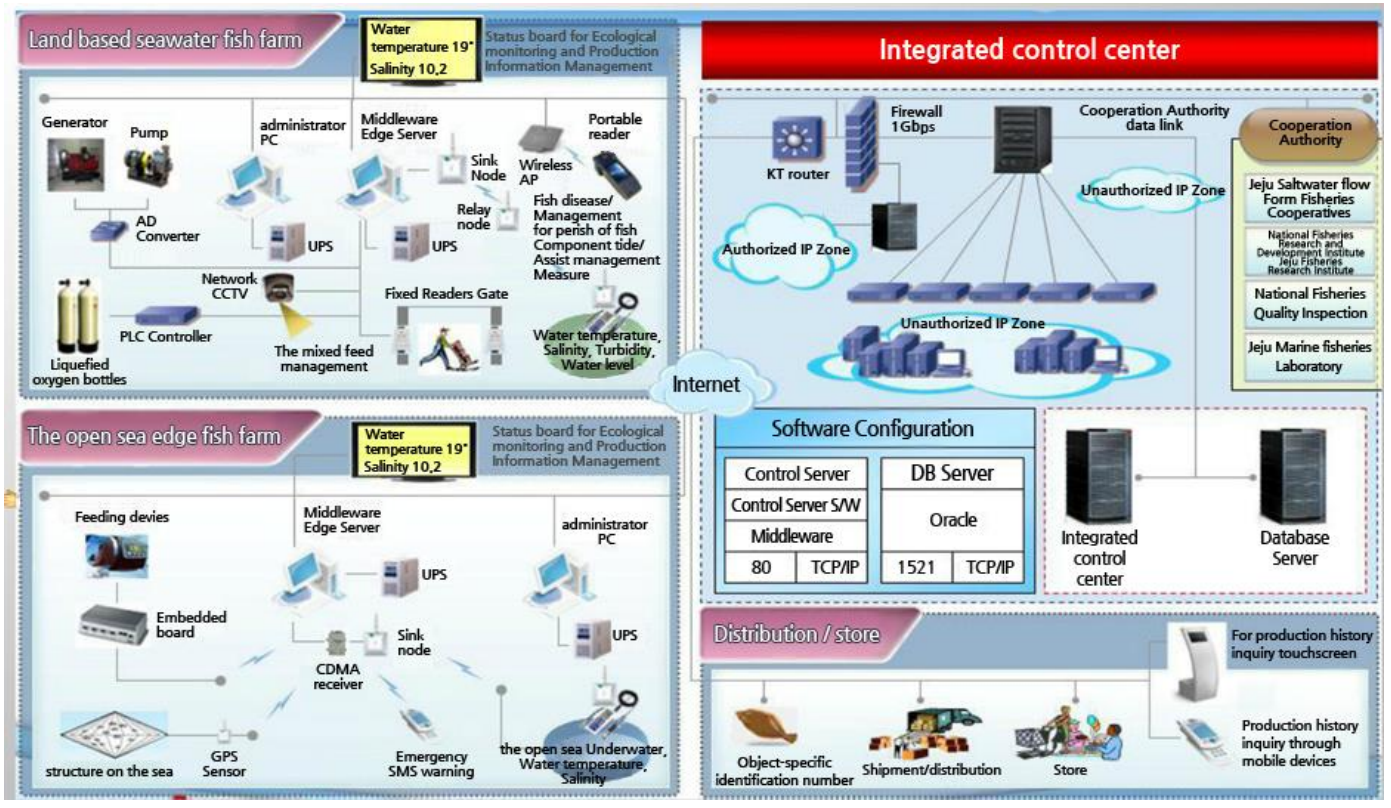

Figure 6. High Quality u-Marine Farming Support System in Tongyeong

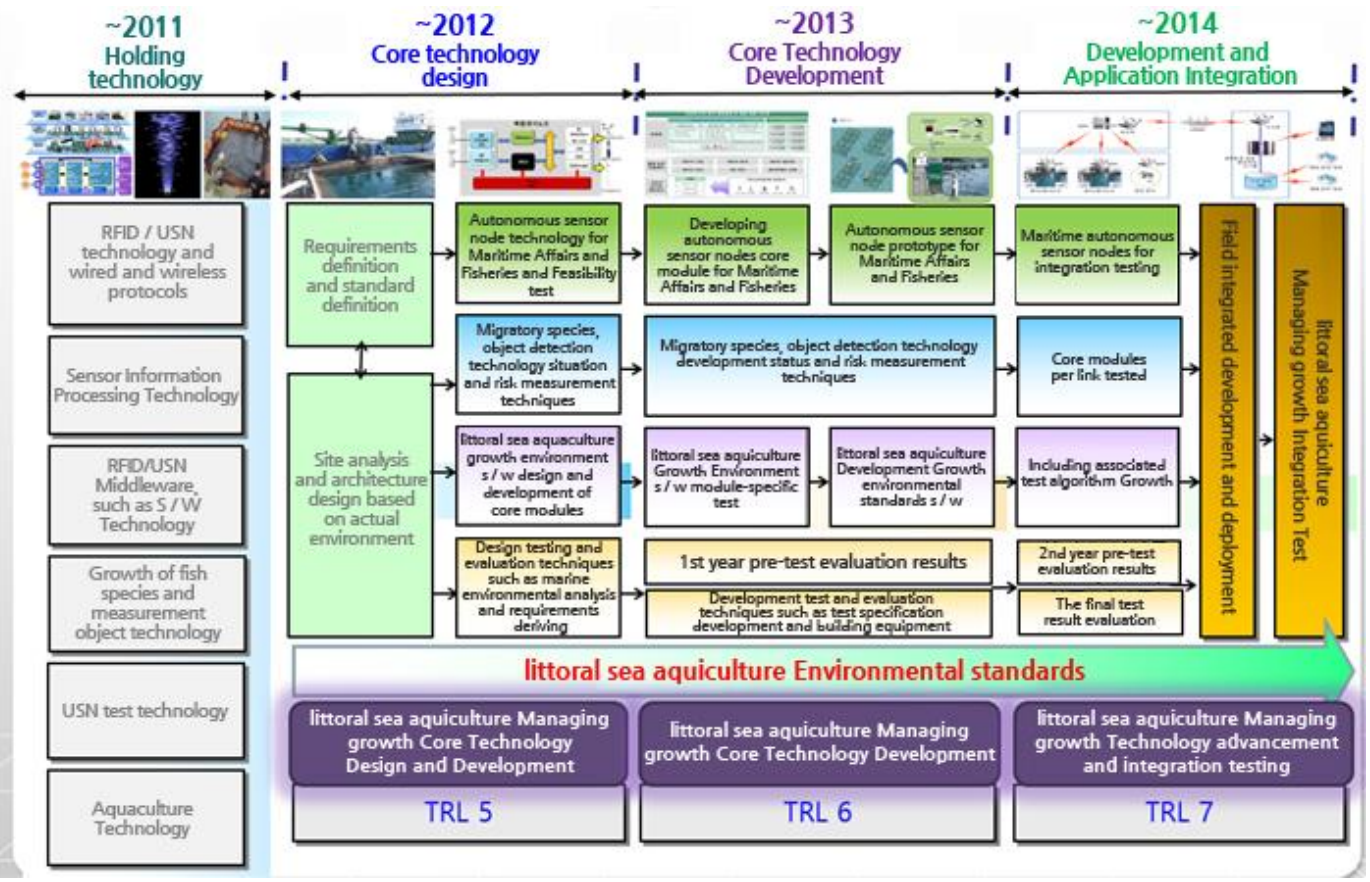

Figure 7. Technological Development Road Map for Core Elements of Growth Management of Coastal and Offshore Fish Farm 


\subsection{Application of New Renewable Energy System for Floating Buoy}

As described in the earlier paragraph, the floating buoy for monitoring the maritime environment has many restrictions in terms of electricity supply. Until mid 2000s, the researches were mainly on low electricity systems but since then, many researches are on systems for supplying electricity by installing solar, wave-power, tidal and wind power generators. In [1]2, the solar and wind power generators were installed in existing maritime facility to diversify power supply. Hybrid system was adopted for electricity supply system and a system for power supply device was separated. Figure 8 shows the system structure proposed in [12].

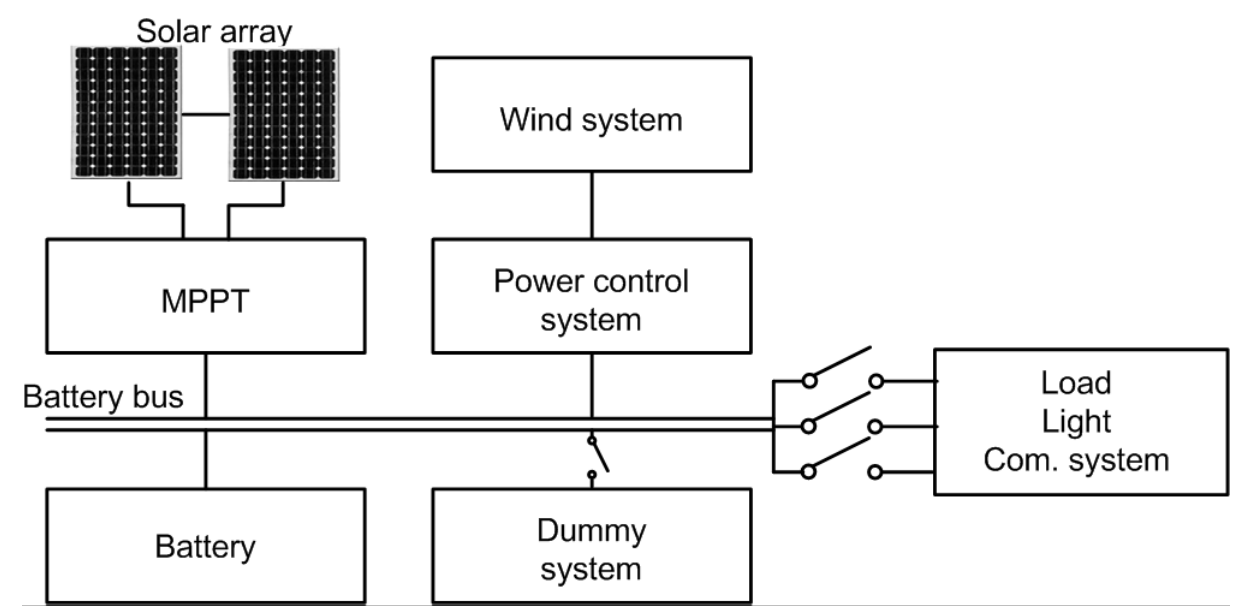

Figure 8. [] System Structure

In [13], the power generation using oscillating water column structure as power supply system using wave-power energy is conducted that has never been applied to small systems. Oscillating water column structure moves floating buoy according to the movement of wave and the water column inside the buoy compresses or expands the inside air based on the relative movement. From this movement, the turbines are rotated to generate electricity. In small wave-power generation systems, electricity is generated by using power generators with permanent magnetic. Figure 9 shows the overview of [13].

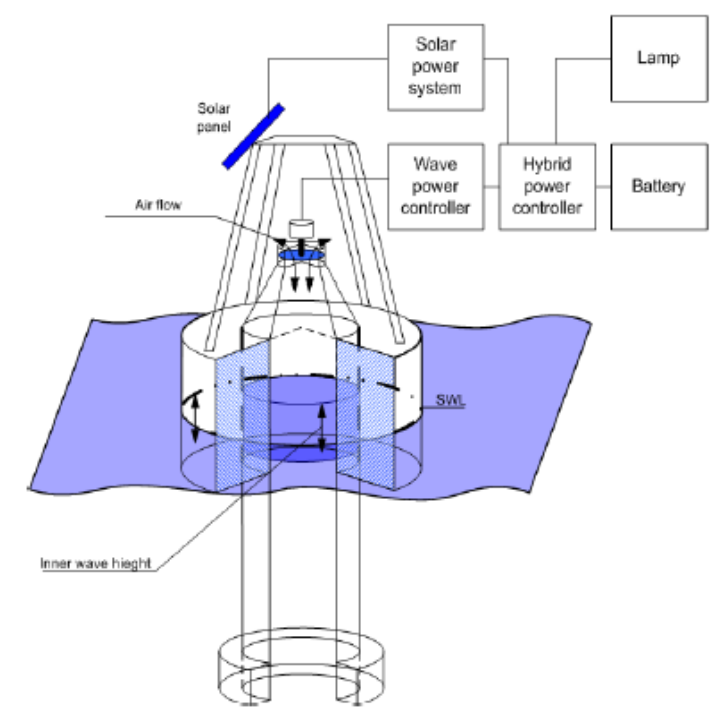

Figure 9. Overview [13] 
Recently, systems supplying power by using various new renewable energy sources rather than electricity generation system using only one new renewable energy source are used. Figure 10 shows an example of using various new renewable energy systems.
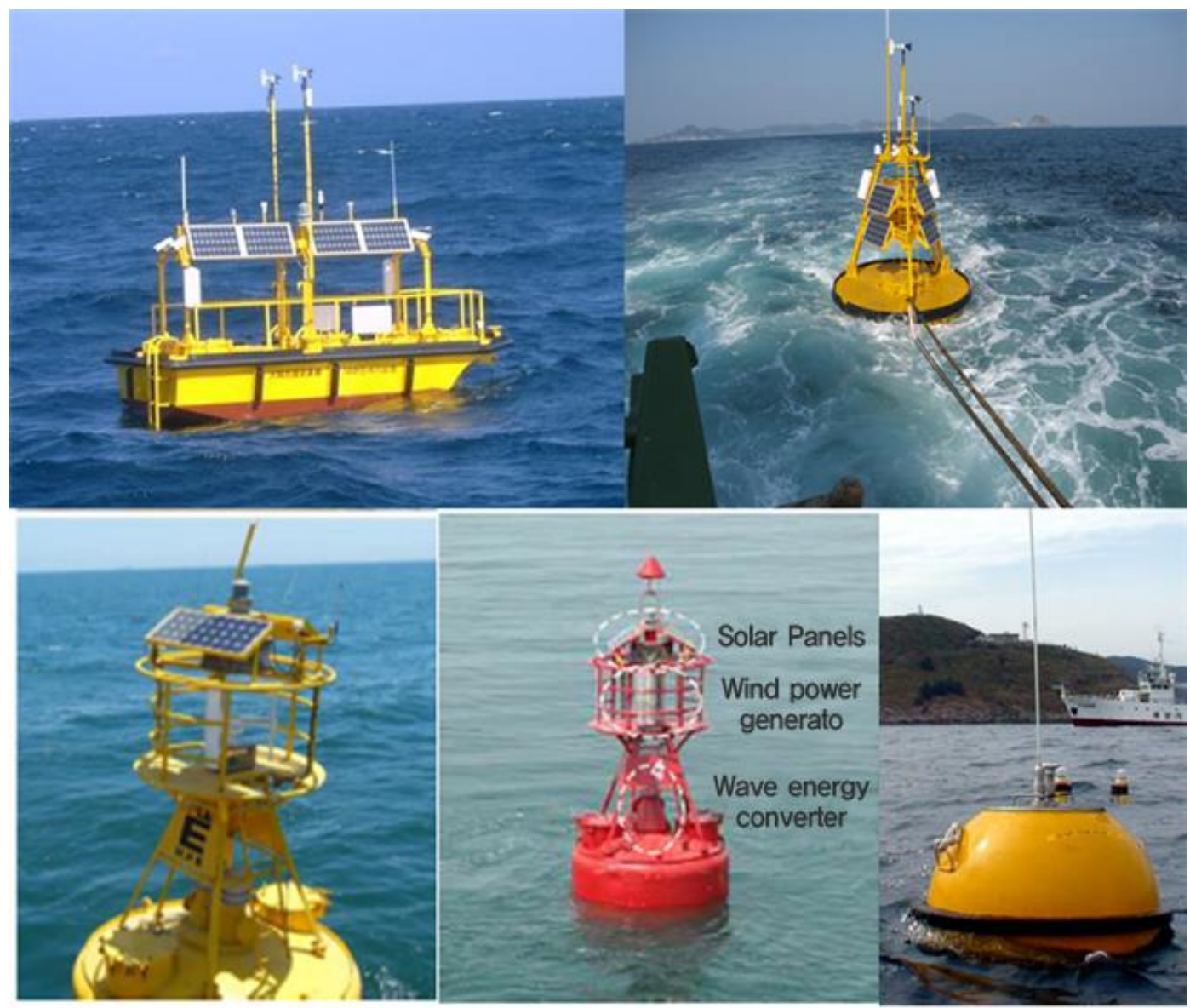

Figure 10. Using a Variety of Marine Renewable Energy Buoy

\section{Design and Development of Maritime Environment Monitoring Buoy Based on Complex Energy Production System}

For stable operation of buoy for monitoring the maritime environment, securing stable and uniform electricity supply device is essential. In this study, the maritime environment monitoring system that combines energy harvesting system and integrated sensor node for supplying electricity using solar, wind and wave-power generation for stable power supply to floating buoys was designed and developed.

To experiment maritime environment monitoring system, it is difficult to test using buoys installed previously, hence a floating body in dimensions $5 \mathrm{~m} \times 5 \mathrm{~m}$ was specially built. The size of floating device $(5 \mathrm{~m} \times 5 \mathrm{~m})$ was determined in consideration for providing proper buoyancy for installing solar power generator, wave-power generator, wind power generator, energy saving system (ESS), harvesting board and integrated sensor node. Also, because it is installed in the maritime environment, its external casing was made in SUS material with high resistance against saltiness, moisture and vibration. Because legal permission is needed in order to install floating buoy in the sea route, it was installed near fish farm and sensors for monitoring the suitable maritime environment for fish farm were mainly installed. The battery storage for energy saving system (ESS) was made into sliding door for easier maintenance and an automatic temperature control 
system for internal system was installed to assure the stable operation environment for the system.

The maritime environment monitoring system designed and implemented in this study is equipped with sensor board for remote monitoring, wireless communication module for Zigbee communication, A/D converter for reading sensor values, Op Amp for amplifying sensor signals and solar, wave and wind power sources to control and utilize energy for extended operation hours without replacing batteries. To use multiple energy sources such as solar, hydro and wind power generators instead of single power source, the electricity levels are synchronized for stable power supply. The energy harvesting system with DCDC converter for using solar, wave, and wind power energy for sensor nodes, AC-DC converter, boost regulator, buck converter, comparator and super capacitor was developed in interface design capable of stable power supply and electricity volume monitoring. Figure 11 shows the maritime environment monitoring system developed in this study and Table 1 shows the detailed specifications for parts used.

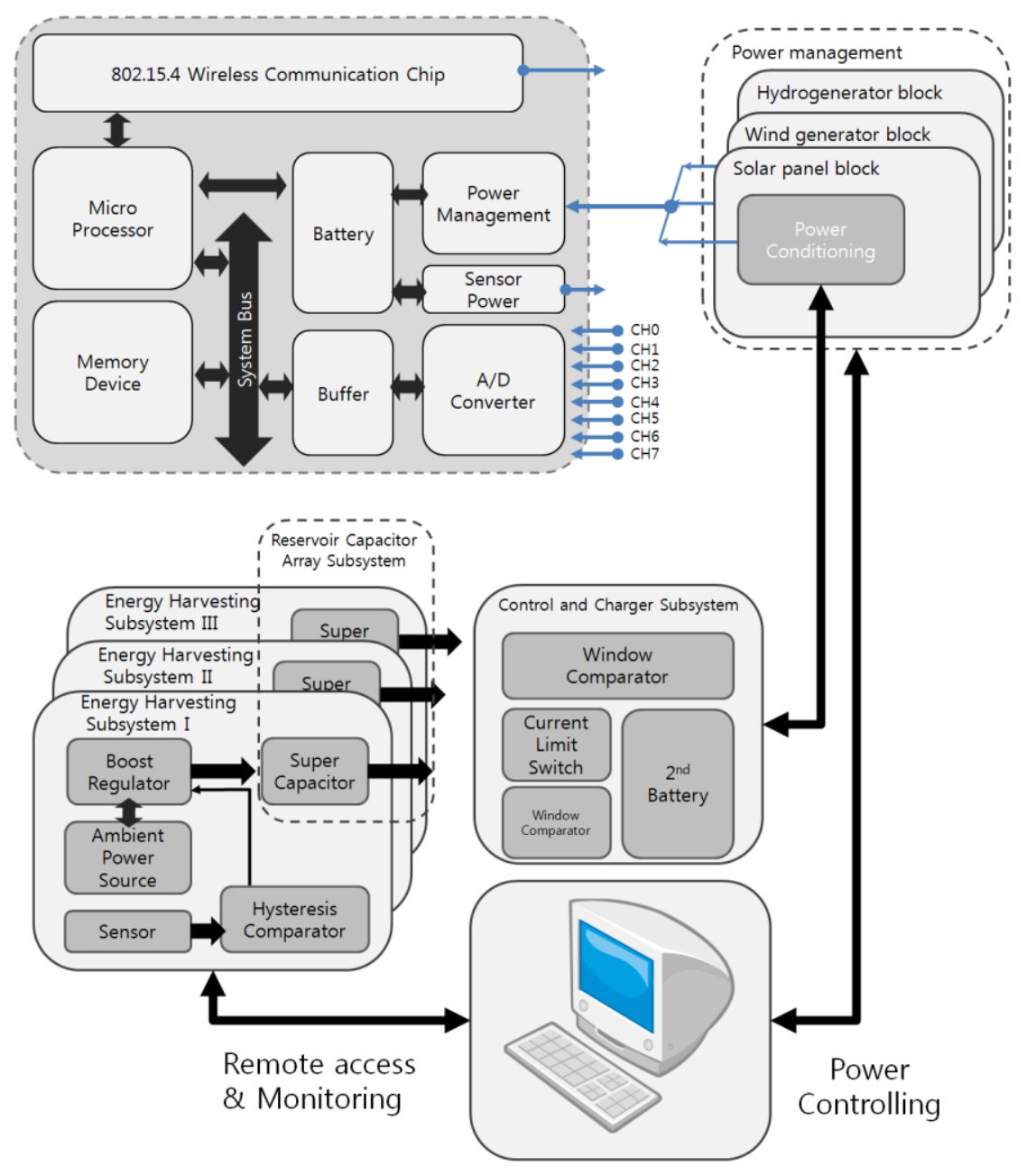

Figure 11. Overview of Marine Environment Monitoring System also 
Table 1. The Marine Environmental Monitoring System BOM

\begin{tabular}{|c|c|c|}
\hline Section & Type & Feature \\
\hline MCU & MSP430F1611 & $\begin{array}{l}\text { Maximum Clock Frequency: } 8 \mathrm{MHz} \\
\text { Data Bus Width: 16bit } \\
\text { Program Memory Size: } 48 \mathrm{~KB} \\
\text { Data RAM Size: } 10 \mathrm{~KB} \\
\text { On-Chip ADC: } 8 \text {-Chx12-bit } \\
\text { On-Chip DAC: } 2 \text {-Chx2-bit }\end{array}$ \\
\hline RF Device & CC2420 & $\begin{array}{l}\text { Radio Frequency (MHz) : } 2400 \\
\text { Max Data Rate (kbits/sec): } 250\end{array}$ \\
\hline \multirow[t]{4}{*}{ Sensors } & $\begin{array}{l}\text { SHT-71 } \\
\text { (Temperature / } \\
\text { Humidity } \\
\text { Sensor) }\end{array}$ & $\begin{array}{l}\text { Vmax(VDD) }: 2.4-5.5 \\
\text { Humidity range }: 0-100 \% \mathrm{RH} \\
\text { Humidity Accuracy }: \pm 3 \% \mathrm{RH}(20-80 \% \mathrm{RH}) \\
\text { Repeatability }: \pm 0.1 \% \mathrm{RH} \\
\text { Temperature Accuracy }: \pm 0.4^{\circ} \mathrm{C} @ 25^{\circ} \mathrm{C}\end{array}$ \\
\hline & $\begin{array}{l}\text { GL5457 } \\
\text { (Ambient light } \\
\text { sensor) }\end{array}$ & $\begin{array}{l}\operatorname{Vmax}(\mathrm{VDC}): 150 \\
\operatorname{Pmax}(\mathrm{mW}): 100 \\
\text { Ambient Temp }\left({ }^{\circ} \mathrm{C}\right):-30 \sim+70 \\
\text { Spectral Peak }(\mathrm{nm}): 540 \\
\text { Response Time }(\mathrm{ms}): \text { Rise } 20, \text { Decay } 30\end{array}$ \\
\hline & $\begin{array}{l}\text { EC Sensor } \\
\text { (SMS-BTA) }\end{array}$ & $\begin{array}{l}\text { Range : } 0 \text { to } 45 \% \\
\text { Accuracy : } \pm 4 \% \text { typical } \\
\text { 13-bit resolution : } 0.05 \% \\
\text { Power : } 3 \mathrm{~mA} @ 5 \mathrm{VDC} \\
\text { Operating temperature }:-40^{\circ} \mathrm{C} \text { to }+60^{\circ} \mathrm{C}\end{array}$ \\
\hline & $\begin{array}{c}\text { pH-BTA } \\
\text { (pH Sensor) }\end{array}$ & $\begin{array}{l}\text { Range : } 0 \sim 14 \mathrm{pH} \text { units } \\
\text { 12-bit Resolution : } 0.005 \mathrm{pH} \text { units } \\
\text { 10-bit Resolution : } 0.02 \mathrm{pH} \text { units } \\
\text { Temperature range }: 5 \sim 80^{\circ} \mathrm{C}\end{array}$ \\
\hline \multirow{3}{*}{$\begin{array}{l}\text { Power } \\
\text { Source }\end{array}$} & Solar Cell & $\begin{array}{l}\text { Input power : } 10 \mathrm{~W} / 18 \mathrm{~V} \\
\text { Output voltage(VDC) }: 12 \\
\text { Output current }(\mathrm{mAh}): 560 \\
\text { panel size }(\mathrm{mm}): 285 \times 350 \times 18\end{array}$ \\
\hline & $\begin{array}{l}\text { Wave } \\
\text { Generator }\end{array}$ & $\begin{array}{l}\text { regulation voltages of } \mathrm{Lo}=13.6 \mathrm{v} \mathrm{Hi}=14.0 \mathrm{v} \text {. for } 12 \mathrm{~V} \\
\text { systems }(27.2 \mathrm{~V} \& 28 \mathrm{~V} \text { for } 24 \mathrm{~V} \text { systems }) \\
\text { cut-in }\left(1 \frac{1}{2} \text { knots }\right) \text { and a high charge rate }(8 \mathrm{Amps})\end{array}$ \\
\hline & $\begin{array}{c}\text { Wind } \\
\text { Generator }\end{array}$ & $\begin{array}{l}\text { Output voltage(VDC) }: 5 \sim 20 \\
\text { Output current(mAh): } 30 \sim 50\end{array}$ \\
\hline \multicolumn{2}{|c|}{ PCB and other devices } & $\begin{array}{l}\text { Resistance, Inductor, LED, Capacitor, Diode, Regulator } \\
\text { and PCB etc. }\end{array}$ \\
\hline
\end{tabular}

The proper electricity consumption of the maritime environment monitoring system was calculated. Transmission for maritime sensor data uses $0.124 \mathrm{~W}$ and wireless sensor interface for communication uses $1.105 \mathrm{~W}$, hence the daily consumption is as in Equation 1.

$1.229 \mathrm{~W} * 24 \mathrm{~h}=29.496 \mathrm{~W} / \mathrm{day}$

The complex sensor node for monitoring the maritime environment uses STM32F407 at $3.6 \mathrm{~V} 160 \mathrm{~mA}$ as MCU, 3.6 V $150 \mathrm{~mA}$ in CDMA module and $3.6 \mathrm{~V} 40 \mathrm{~mA}$ in RF module, hence consumes total approximately $4 \mathrm{~W}$. Daily consumption can be calculated as in Equation 2.

$$
4 \mathrm{~W} * 24 \mathrm{~h}=96 \mathrm{Wh} / \mathrm{d}
$$


Based on this, total $126 \mathrm{~W} /$ day of daily electricity consumption is expected, and with $30 \%$ duty cycle, total $60 \mathrm{Wh} /$ day of daily electricity consumption is expected. Is assuming three sunless days, approximately $180 \mathrm{Wh}$ of capacity is necessary for energy saving system (ESS). For this energy supply system, products with capacities of $15 \mathrm{~W}, 15 \mathrm{~W}$ and $3 \mathrm{~W}$ for solar power system, wind power system and wave power system were used respectively with 4 hours, 6 hours and 10 hours of charging time for solar power, wind power and wave power respectively.

\section{Energy Harvesting System Algorithm Development}

All electricity inputs supplied from new renewable energy source are in DC inputs and MPPT is conducted by PWM control signal from MCU in each column based on this. The MPPT algorithm of solar energy harvesting system is based on the $\mathrm{dP}$ P\&O algorithm. During energy harvesting process using solar panels on the maritime environment, the panel itself will roll with the wave as it is floating on water instead of being fixed. Hence, it has the issue of fluctuation in incident light. Previous algorithm will conduct tracking by increase in voltage during MPPT, and in case of decrease in incident light, the voltage near maximum instead of the maximum electricity will be harvested. To solve this issue, the intermediate point was conducted during MPPT to measure fluctuation in incient light to gain the maximum electricity. First, by classifying $\mathrm{ThN}=$ negative threshold $\mathrm{dP}, \mathrm{ThP}=$ positive threshold $\mathrm{dP}$, the direction of MPPT from incident light was identified. Then, $\mathrm{dP}$ can be gained from formula 3, and the schematic diagram for this is shown in Figure 12. In case of applying this algorithm, even if the incident light increases near the peak point, the error of reaching the voltage location in reverse direction will not happen. Figure 13 shows the $\mathrm{dP} \mathrm{P} \& \mathrm{O}$ algorithm.

$$
d \mathrm{P}=d \mathrm{P}_{1}-d \mathrm{P}_{2}=\left(\mathrm{P}_{\mathrm{x}}-\mathrm{P}_{\mathrm{k}}\right)-\left(\mathrm{P}_{\mathrm{k}+1}-\mathrm{P}_{\mathrm{x}}\right)=2 \mathrm{P}_{\mathrm{x}}-\mathrm{P}_{\mathrm{k}+1}-\mathrm{P}_{\mathrm{k}} .
$$

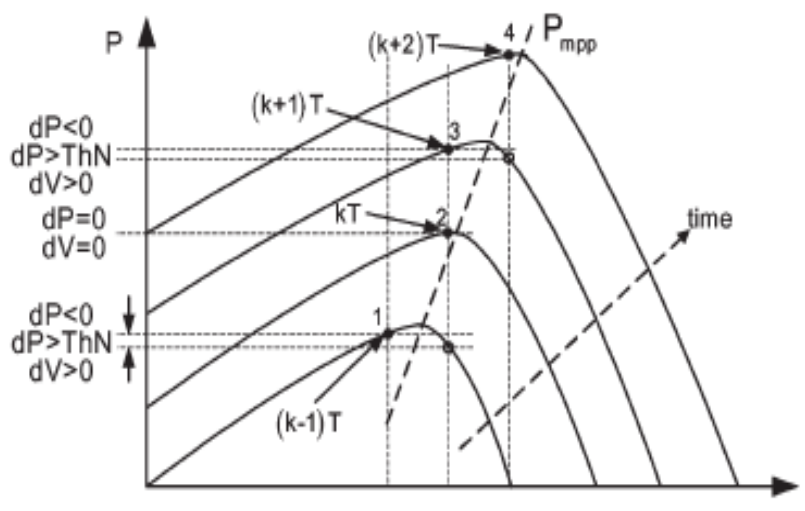

Figure 12. MPPT Performing Procedures 


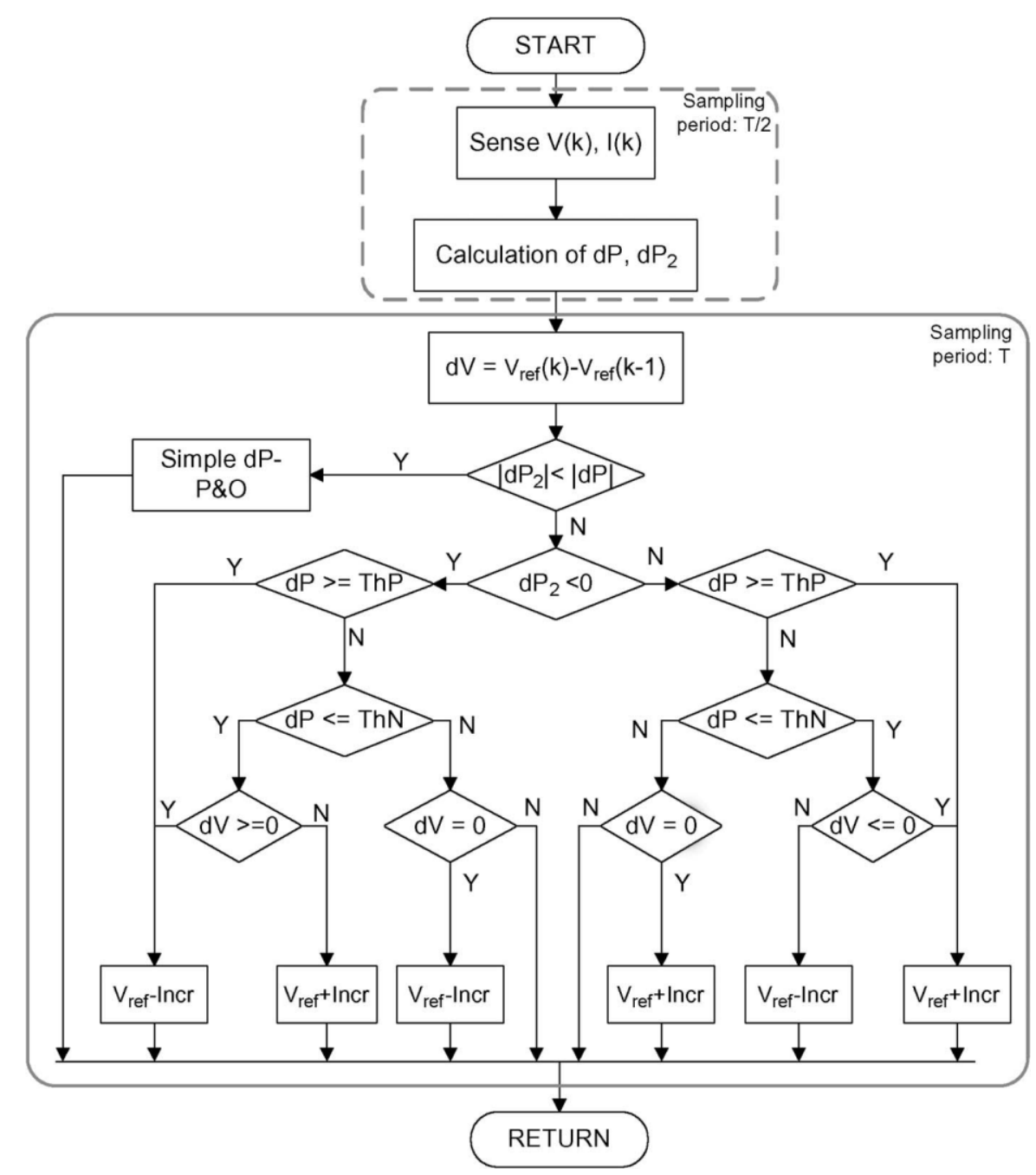

Figure 13. dP P\&O Algorithm

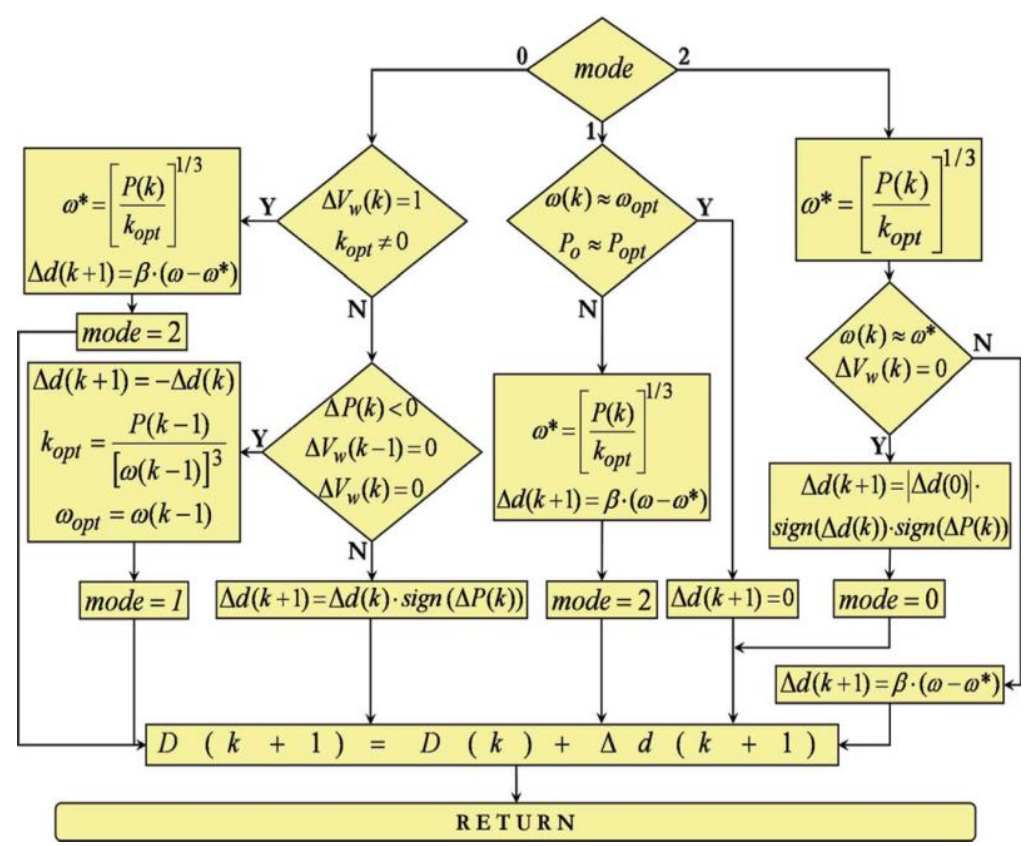

Figure 14. Wind and Wave MPPT Algorithm 
For wind power generator, MPPT was conducted by analyzing the MPP from controlling speed by change in wind strength and speed due to the characteristics of wind. In particular, to gain the maximum electricity regardless of the environment, the system was based on the speed of generator $w^{3}$, and its respective coefficient $k_{\text {opt }}$. Figure 14 shows the MPPT algorithm for wind power and wave power capable of generating the maximum electricity in three modes.

For wave power generator, the Double Mounted Backward Bent Duct Buoy (BBDB) method for utilizing the wind speed of internal air generated from oscillation of water in left and right axes according to the flow of water from wave was used as in Figure 14. The energy generated from wave power calculated from this structure is shown in Equation (4).

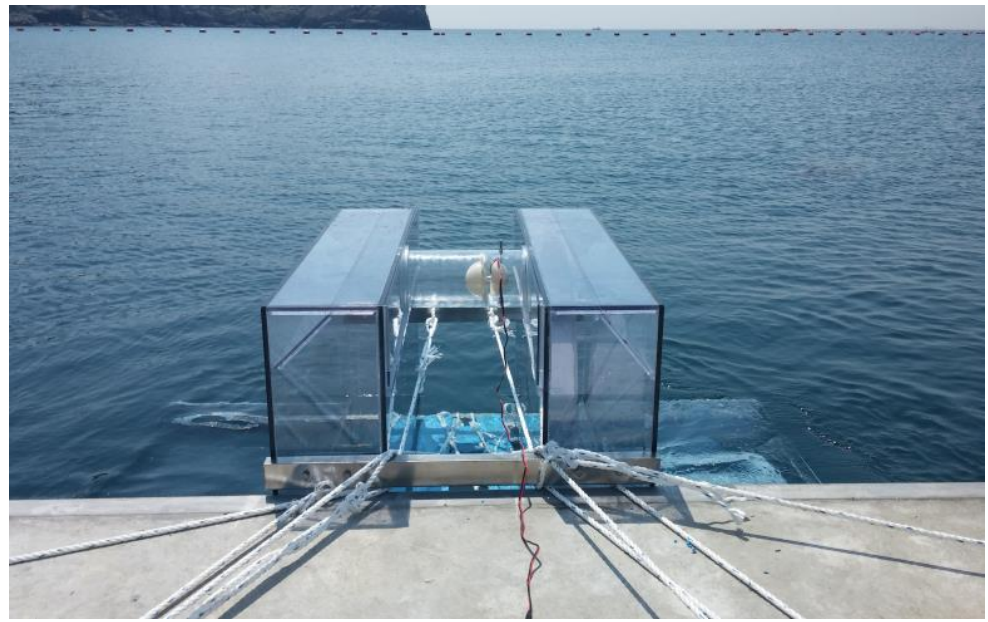

Figure 15. Wave Energy Test Picture of How BBDB

$$
\begin{aligned}
& E_{\text {turbine }}=\frac{A_{r}}{T} \int_{0}^{T} p(t) \frac{\Delta}{\Delta t}\left(\frac{v_{1}(t)+v_{2}(t)}{2}\right) d t
\end{aligned}
$$

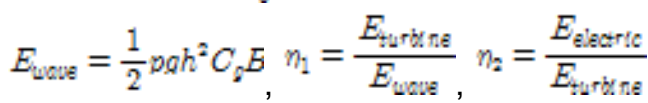

energy sources, the complex parallel energy harvesting board was developed for stable power supply. This harvesting board is conducted based on three energy sources: solar, wind and wave. All of the three power input sources feature permissible DC voltage range of $4.95 \mathrm{~V}-32 \mathrm{~V}$ and permissible current of 2 A each. Output is via battery equivalent to the output of battery specification at $12 \mathrm{~V}$. Each input and battery can conduct monitoring (UART communication capable) via current sensor, and MPPT is provided by conducting PWM control via MCU based on this.

\section{Conclusion}

With the increased utilization of the maritime environment, various floating buoys and monitoring systems for monitoring the maritime environment are being installed, due to the reduction in harvest of agricultural and livestock goods from change in soil environment due to climate change and explosive increase in population due to rapid industrialization, the expansion of maritime farming industry is in rapid increase as an alternative. Fish farm environment monitoring assures the stability of fishery products produced and enables securing of stable production volume from proper measures. For the smooth monitoring of the maritime environment, stable electricity supply to the maritime environment monitoring system is needed. However, unlike land environment, there were many 
difficulties in conducting stable power supply to buoys and monitoring system in the maritime environment. Hence, until the early 2000s, many researches were on ultra low electricity systems but since mid 2000s, the systems for delaying the battery exchange cycle or increasing operation hours were developed by establishing power supply systems using new renewable energy sources available on waters. In this study, the harvesting board and algorithm for electricity management for efficient harvesting of energy from installing solar, wind and wave power generators applicable to floating buoys were developed. The system designed and developed in this study enables electricity supply for extended operation than previous systems by generating electricity from various electricity sources and integrating the management.

\section{Acknowledgments}

This paper is a revised and expanded version of a paper entitled [Design and Development of Small Energy Harvesting System for Marine Environment] presented at [Su-Yeong Yang, Nam-Hyun Yoo, Won-Jung Kim, August 19th 2016 at Harbin University of Science and Technology, Harbin, China.].

\section{References}

[1] S. H. Park, "Electronics System Design of a Generic Meteorological Buoy", Journal of the Korean Institute of Electronics Communication Sciences, vol. 5, no. 1, (2010), pp. 51-57.

[2] J. S. Shim, D. Y. Lee, W. S. Pak, and K. S. Park, "Development of Ocean Data Buoy and Real-Time Monitoring Technology", Journal of Korean Society of Coastal and Ocean Engineers, vol. 11, no. 1, (1999), pp. 56-67

[3] C. J. Moon, Y. H. Chang, T. S. Park, M. S. Jeong, H. J. Joo, O. S. Kwon, D. J. Kwak, G. S and Jeong, "A Study on Design of Offshore Meteorological Tower", Solar Energy, vol. 34 no. 2, (2014), pp. 60 65.

[4] Y. H. Yu, Y. S. Gang and W. B. Lee, "Development of a Floating Buoy for Monitoring Ocean Environments", Journal of the Korean Society of Marine Engineering, vol. 33, no. 5, (2009), pp. 705712

[5] J. Baker, S. C. Yim, E. Amon, S. Moran, T. Lettenmaier and A.V. Jouanne, "Mooring Analysis Of a NOMAD Buoy Through Field Testing and Numerical Simulation", Proceedings of the 33rd Intl. Conference on Ocean, Offshore, and Artic Engineering, San Fransisco, U.S. A, (2014).

[6] T. LettenMaier, E. Amon and A. V. Jouanne, "Power Converter and Control System Developed in the Ocean Sentinel Instrumentation Buoy for Testing Wave Energy Converters", Proceedings of the 3rd IEEE Energy Conversion Congress and Exposition, Denver, U.S.A, (2013).

[7] C. S. Kim, J. S. Jeong and S. H. Park, "A Study on Remote Monitoring System for Protecting Aquaculture Farms", Journal of the Korean Society of Marine Environment \& Safety, vol. 10. no. 2, (2004), pp. 55-70.

[8] J. H. Seo, S. H. Han and M. S. Jang, "Specific Handset Design for Environmental data Monitoring in Aquafarm", Journalof the Korea Institute of Electronic Communication Sciences, vol. 2, no. 2, (2007), pp. $145-151$.

[9] J. S. Oh, J. H. Kwak, S. J. Jung and Y. J. Han, "A Study of Method for Construction of Wireless Vision Monitoring System for Fish-cage in Open Sea”, Journal of the Korean Society of Marine Engineering vol. 32, no. 6, (2008), pp. 989-996.

[10] J. B. Yim and T. K. Nam, "Implementation of Unmanned Aquaculture Security System", Journal of the Korean Society of Marine Environmental \& Safety, vol. 13, no. 1, (2007), pp. 61-67.

[11] S. I. Hwang, O. Y. Kim and S. Y. Lee, "A Case Study on the ICT-Based Smart Aquaculture System by Applying u-Farms", The Journal of the Korean Institute of Communication Sciences, vol. 39C, no. 02, (2014), pp. 173-181.

[12] J. S. Oh and K. J. Jo, "A study on Solar-Wind Hybrid Power Generation System”, Journal of the Korean Society of Marine Engineering. vol. 33, no. 8, (2009), pp. 1226-1231.

[13] K. J. Jo and J. S. Oh, "Development of Small Wave Power Controller for Ocean Facilities", Journal of the Korean Society of Marine Engineering, vol. 35, no. 6, (2011), pp. 835-841. 


\section{Authors}

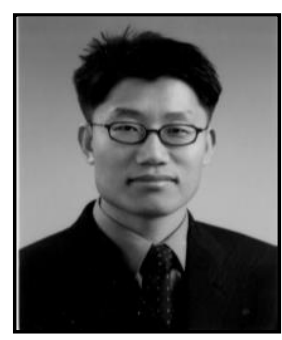

Yang, SuYoung, he Graduated from Computer Sicence of Suncheon National University(Master's degree) on August. 2002. He also graduated from Computer Sicence of Suncheon National University(Doctor Completion) on January. 2009. He is a President of Elsys Co.,LTD. Interested field : IoT, context awareness, Ubiquitous.

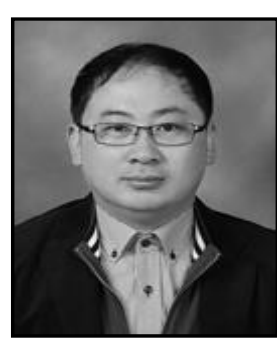

Yoo, NamHyun, he is a Assistant Professor at KyungNam Unversity since 2013 until now.

2011 2013: Senior Researcher at KOSTEC

2010 2011: General Manager at Elsys Co., Ltd.

2008 2010: Visiting Professor at University of Oklahoma

Research Interests: Cooperative Intelligence, Automation, Context Awareness, Marine Robot

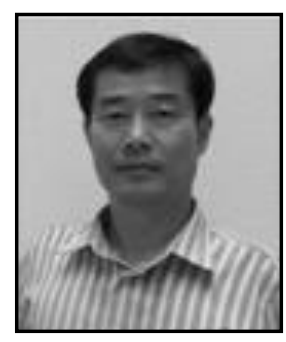

Won-jung Kim, he graduated from Computerization \& Statistics Department of Jeonnam National University (Bachelor's degree) on Feb. 1987.

Graduated from Computerization and Statistics Graduate School of Jeonnam National University (Master's degree) on Feb. 1989. He also graduated from Ph.D. on Computerization and Statistics of Jeonnam National University on Aug. 1991 and a Professor of Computer Engineering Department of Suncheon National University. He is Interested in RFID/USN, IoT, Context Awareness, BigData and Location Based Services. 